\title{
Iconics: Icon Evolution in Digitality
}

\author{
Steven John Thompson
}

\author{
iconicologist@gmail.com
}

\begin{abstract}
Image manipulation, archiving, and sharing are all critical technological aspects of Western culture and postmodern civilization. Consequently, creation, identification, dissemination, and proliferation of powerful images across media channels today indicate a burgeoning area of information technology.

While words alone are capable of conveying adequate information across media channels, the news industry crafts around the dual enterprise of both word and image. Audio-visual supports of these communication devices constituting new media are standard means of rhetorical expressions in acquiring and sharing information in daily life.

Overwhelming sensory experiences associated with broadcast media ensure that neither 1) time to study individual factors that render media as iconic, nor 2) interest in interpretation of such dynamics prior to public release. That leads to deeper issues of access, privilege, and motive, yet only through serious scholarly inquiry can we gain understanding of rhetorical roots and expressions of the diverse entities producing media that eventually becomes iconic.
\end{abstract}

Keywords: Icon, iconic, iconology, iconography, iconicology, media, terror, cyberspace, Internet, collusion, rhetoric, war, violence, digitality, virus, autopoiesis, gestalt, instantiation, mutation, irruption

Acknowledgement: Portions of this paper are excerpted from a forthcoming book on iconics.

Study of iconic media today has a scope of inherent rhetorical wonders, threats, and dangers that beg interpretation. The rhetorical elements that contribute to raising media to an iconic level should be countable and accountable attributes.

Iconic media is global in distribution. Yet, a simple and localized systematic approach to dissemination of the rhetorical devices used in its construction and proliferation may become seed for future inquiry into such rhetorics.

Media images previously bound by the constructs of analog technologies have taken on new dimensionality through participation and promulgation within media outlets of digitality. This new digital territory for the iconicity of images is changing the way cyberspace adopts an icon, and the way humanity avails itself of it.

\section{Research Objectives}

My overall task has been to establish links and connections between the traditional understanding and historical roots of the icon, iconography, and iconology, with the iconic and its presence and representation across global digital media channels. Consequently, recognizing contingencies that make an icon defensible in definition during its time of theoretical exegesis is imperative, as embrace of understanding of the icon in time has been dictated by its evolutionary trajectory in and across history. Once that history extends into digitality, the icon is no longer eligible as static image, no matter how revered; yet, now a metaphorical expression of phenomenological discourse inhabits it, and its perception.

This study evaluates the icon from its visually rhetorical stance as static image to its transformative state of global empowerment today. It is not possible to evaluate the digital icon without consideration of the media and technology that propel it to the iconic. It is not possible to humanly calculate the extent to which icons as iconics influence decisions by those persons in power who recognize their persuasive power over networked audiences.

This paper evaluates the conditions which render extreme iconicity to various media, the phenomenological channels that contribute to that process, and the overall resulting hyper-objects. A 
breakdown in important areas of icon influence today would be an exploratory starting point for assessing the role of the transitory icon posited in the analog before it effectually takes on today's digital potentiality.

\subsection{Icons in Time}

The volume of texts providing historical data for the icon is extensive. Many of these texts cross over into religious and cultural areas as well. The role of icons as rhetorical emblematic powers will be crucial to further understanding the strength of the icon as it evolves into the iconic of today. See Figure 1.

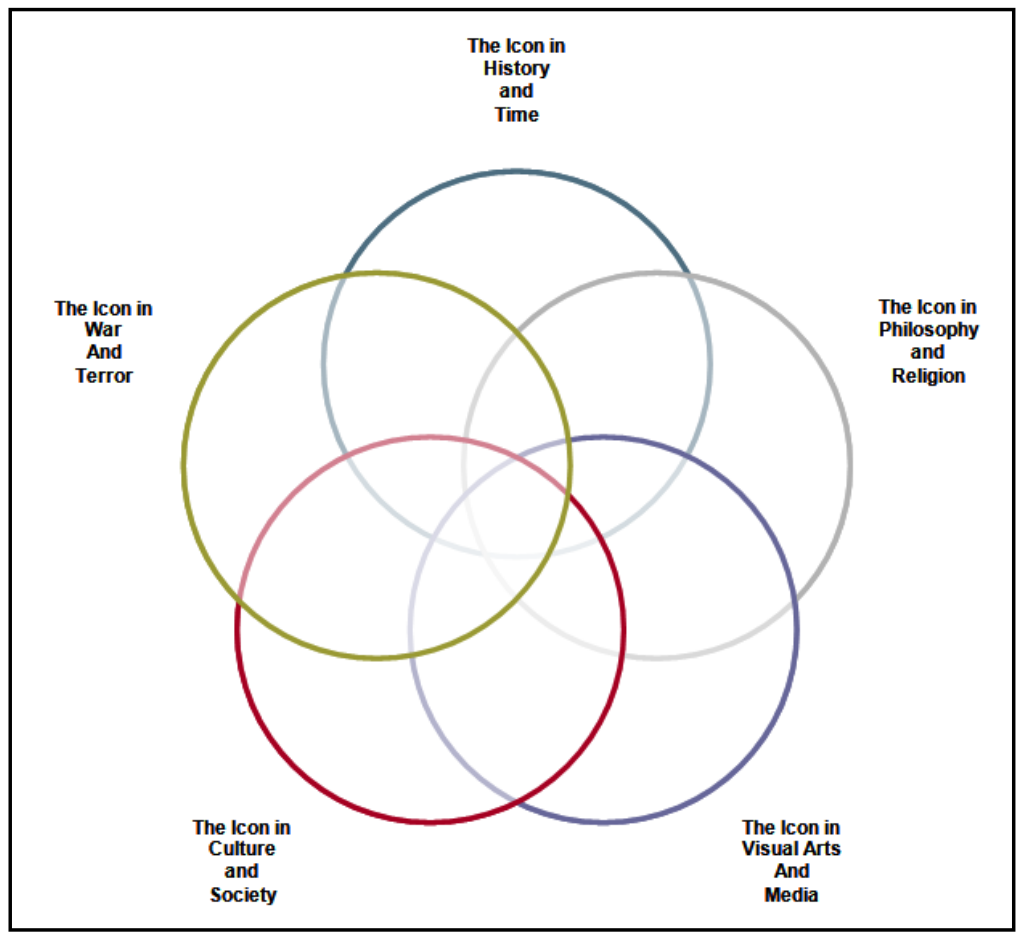

Figure 1: Sectors of icon creation, expression, influence, and power

As icons exist in the twenty-first century, their roles and powers relegate largely to computer images and celebrities; iconics, however, are the moments and mediated experiences that mirror the roles and powers that traditional icons received in prior centuries, only these attributes exponentially increase because of the capabilities and ubiquity of digital media channels.

Despite one's socio-cultural or spiritual perspective on religious iconography, the role of icons in mediated messages is important. Today the term 'icon' attributes to everything from the computer shape onscreen that a person can click with a mouse, to the computer itself. The computer, according to Bill Nichols in Screen, "is also an icon and a metaphor that suggests new ways of thinking about ourselves and our environment, new ways of constructing images of what it means to be human and to live in a humanoid world" (1988).

Nichols builds his essay on the work of Walter Benjamin in The Work of Art in the Age of Mechanical Reproduction, updating Benjamin's essay with his own thoughts in The Work of Culture in the Age of Cybernetic Systems. It is Benjamin's piece however, that is seminally iconic in the realm of philosophy, and why Nichols traverses the text for booty. Actually, historically and platonically, the icon itself is a metaphor; and, I believe one reflected in the fluid nature of an iconic as the rendered or evolved icon traversed into digitality. 
What seems practical then, at least for iconic imagery as evidenced through mediated messaging, is what E. H. Gombrich noted regarding symbolic images, that "the interpretation can never be carried beyond a certain level of generality" $(1972$, p. 3). This is of primary, perhaps sociocultural, importance to those entities creating icons for global appreciation since icons subsume historical, categorical, chronological roles of identity.

Furthermore, digitized icons in media can act as metaphors. Theodor van Leeuwen claims that metaphors will "make new and unprecedented events appear familiar, natural, and acceptable...." (2006, p. 518), and this is exactly what is happening in media today, especially as the transition from analog to digital makes familiarity more person with high definition displays and ubiquitous Internet access that allows personalization and customization of the event.

Gombrich provides a clear expectation for the role of the iconologist, one equally applicable for later defining the role and purpose of the media iconicologist:

"The genre of programmes was based on certain conventions, conventions closely rooted in the respect of the Renaissance for the canonic texts of religion and of antiquity. It is from a knowledge of these texts and a knowledge of the picture that the iconologist proceeds to build a bridge from both sides to close the gap between the image and the subject matter. Interpretation becomes reconstruction of a lost piece of evidence. This evidence, moreover, should not only help the iconologist to identify the story which may be illustrated. He wants to get at the meaning of that story in that particular context..." (p. 6-7)

\subsubsection{Digital Historicity}

While state borders -- such as those erected in Europe and Africa -- are disintegrating as result of rising rogue political powers and other sociopolitical factors, many cultural icons are transporting with their peoples across borders -- and beyond borders -- to such a radical degree that levels of integration vs. homogenization are an entirely separate area of inquiry. Iconics relevant to these peoples, wherever they abide on the planet, are no less significant historically or culturally, whether mediated across newspapers, radio waves, television, or the Internet as linkages across any diaspora. It only took publication back in 2005 of 12 Danish cartoons with potentially offensive Islamic content to unify and rally Muslims across the globe despite state borders and anyone's particular persuasion regarding effectual humor.

This type of selective interpretation is here to stay. The collected consciousness surrounding a mediated message -- photography, print, audiovisual -- has a point of view, even as Paul Virilio contends for "the televised instantaneity of a prospective observation, of a glance that pierces through the appearances of the greatest distances and the widest expanse" (1991, p. 31). It bears witness, as millions of receivers attach meaning to it. Photography, video, and other media as event constitute such messagings at their iconic cores.

In reviewing the historical September 11 incident of 2001, Derrida viewed the traumatic event as "not what is presently happening or what has happened in the past but the precursory signs of what threatens to happen" (2003, p. 96-97). This chronology is most indicative of twenty-first century global events characteristic of a society not headed toward a posthistorical state, but rather, radically embedded within the historical. In addition, it is this continuous repetition of the event -- as mediated message identifiable by millions -- that renders it iconic.

That all globally mediated messages insist on a point of view and testimony is primary consideration for why media iconics -- especially the photographic -- precondition any posthistorical positioning: their powers and effects define, evidence, and assimilate by their respective cultures en masse. Consequently, there can be no posthistorical period of humanity within the constraints of time because the scope of media iconics simply does not permit non-historic or posthistorical registry and accountability for the masses.

It is where cultures not sharing the voice of this effected collected consciousness persist that tensions arise and the iconic instrument that divides is subject to deeper critical analysis. While many cultures neither seek nor demand affirmation or approval for their collective interpretation of 
media iconic events or contents as they experience them -- nor perhaps, should they need to offer interpretation -- this remains one of the highest areas of contention and division among people, and is perhaps our most unaddressed yet explosive communication issue.

Near the advent of network television, Erwin Panofsky observed that "iconographical analysis.... presupposes a familiarity with specific themes or concepts as transmitted through literary sources, whether acquired by purposeful reading or by oral tradition" (1955, p. 35). Panofsky was certainly correct up until that time, especially since radio could easily fall into the line of oral media associated with tradition, and reading and the arts were primary media incorporating icons.

Iconic images have taken on new media roles and anyone today can create them. Especially, as Davies, Bathurst and Bathurst note, through ubiquity of the personal computer and multimedia manipulation software, where "the handicap of the picture makers and uses has finally been removed" (1990, p. 37). People and their societies today are dealing with something much more pervasive and spectacular than was capable in the past with an entire media creation process -- from conceptualization through to implementation -- now in everyone's hands.

Iconic artifacts related to war also have taken on a new dimension since World War II. They certainly work as archiveable testimony to propaganda and the past, and definitely provide news fodder for the present. And the matter of propaganda and persuasion cannot be neglected here, as both rhetorical devices are critical to the successful creation and dissemination of iconics today. This is partly based on their historical trajectories from previous world wars where the media had become an ultimate vehicle for 'war rhetorics.'

Van Leeuwen credits the European model as an interdisciplinary one linked "with historical and politicological approaches to war propaganda" that include "non-linguistic forms of war rhetoric" where images "play an important role in strategies such as the demonization of enemies and the exaggeration of atrocities" (2006, p. 519). Harold Lasswell initially helped set some of the tone for this discourse with his 1927 publication on 'propaganda technique,' wherein he rhetorically asked, "Is it desirable for the leaders of propaganda to be recruited from among the most powerful newspaper proprietors and editors?" (1938, p. 29).

Lasswell ultimately concluded, "It is true that newspapermen are the most desirable" (p. 31) but said the need for choosing those highest in power is not required. The media layman is quite capable of being the purveyor of propaganda and persuasion, albeit through whatever visual rhetoric s/he employs, and especially across digital channels, where the power is exponentially exacerbated beyond analog rhetorical methods.

What iconics do for a future renders them extremely powerful and dangerous now. Again, and as we will see, it is their electronic reproducibility and capacity for manipulation by anyone today that adds an elusive -- albeit more frightening -- dimension. In fact, their archivability and reproducibility are collective qualities that partly empower and help redefine icons.

A digital icon or similarly appropriate image is no longer an icon in a contemporary sense because it is not an icon in any traditional sense anymore. Once an icon enters the digital realm it is capable of resonating on the global consciousness as it undergoes transformation from the state of a static icon to one that is dynamic, resolute, and complete: the icon evolves into an entity, an existential phenomenon posited permanently in digitality. It adapts to digitality with an ease that further affords its survival as a vast collection of powerful ones and zeroes; i.e., it becomes an iconic.

As noted earlier, the advancement of digital persuasive rhetorics over analog are substantive, and need not be relegated to one singular medium. Movement of iconics across digital channels beyond media events is strong as all digitized media empower today.

\subsubsection{Defining Iconics}

Contemporary, pre-existing uses of the term iconics relate to subject matter not indicative of my use of the term, and the same goes for the term iconicology, which has no prior usage. Each of my terms indicates the phenomenological discourse that is possible and practical today for study of 
new digital media in its intimate relationship with global media messaging, mass societies, terrorism, and, in some possible scenarios, new artificial intelligence.

Study of iconics draws attention to the current phenomena as real, active forces virtually at work in the global consciousness. Iconics directly inform our understanding of media's role in digital society by providing a framework capable of 1) ascertaining the rhetorics of -- and responsibilities for - important storytelling, narratives, and myths associated with terrorism and terrorist messages, 2) leveraging the psychosocial impacts of media rooted in cyberspace, and 3) framing cognitive instantiations of rhizomic network irruptions as new existential phenomena.

I have defined an iconic as an instantiation, a media moment in the global consciousness that rises to new stature, due to its placement in that consciousness through a gestalt. An iconic rises above contingency, in that it occurs at a given time and place (not necessarily a physical space) in human history, as it then acquires a new contingency whereby it reaches "glorification," or if I may borrow from Walter Benjamin, it receives an almost magical aura -- at a later date than its initial placement on any linear timeline. For Benjamin, aura decreased with the more public access available to a work of art (1969); however, I am suggesting the opposite here: that precisely because of ubiquitous global media reception and ownership the image becomes an iconic: relatively omnipotent, highly revered.

In a sense, again to borrow but this time from Christian theology, an iconic is a kind of transfigured icon, instantiated at some point in the global consciousness of human history as a vibrant, virtually alive digital relic or artifact. It maintains this transfigured state as long as it can be pulled from -- or into -- the global consciousness, which means that it exists as long as there is a cyberspace, and it becomes greater in power and efficacy because of the many benefits the digital realm affords it, which is my contention about its potentiality for increase in what Benjamin calls aura.

Ultimately, utility of iconic images is what is at the virtual heart of their artistic creation and manipulation. An iconic does not need to be an icon, sign, or symbol. It does not need to be an image or visual rhetoric. It does not need popular or visual culture. An iconic is a rhetorical, globally conscious instantiation in a media moment, digital in essence, multimediated, ubiquitous to the point of omnipresence, and fully archived - all at once! At least, that is its starting point....

\subsubsection{Iconology vs. Iconicology}

Icons have evolved beyond their semiotic beginnings. Traditional theoretical notions of the cultural icon that exist in communication models of Charles Peirce, Erwin Panofsky, Kenneth Burke, Roland Barthes, and other theorists in iconology lend themselves to a contingent definition and discussion of iconics.

One man's symbol is another man's icon. Umberto Eco noted that "Saussure called symbols what Peirce called icons...." (1984, p. 137). The reality is that icons are everywhere; yet one man's media icon is everyman's iconic. Study of the meaning of icons, the art of iconography, and the role of iconology are what lie at the root of the comprehensive field of iconicology. I argue further to say their effects on societies are of extreme importance in understanding iconics at play in any form, network, or system. While media iconics as simple artifacts readily identifiable across the collective consciousness are in themselves neither good nor evil, apart from any deterrence of atomic weaponry, their power for the mediation of the perception of good or evil may be unsurpassed in the realm of modern electronic and virtual warfare.

These iconics are continually transforming peoples and societies. Their proliferation, or reproduction, is critical to the collective consciousness that ultimately determines war and peace, comfort and disease, and other global dichotomies of extremity that go beyond culture and personal taste; they have an impact on the highest global population sectors.

Traditional theoretical views of the icon, even postmodern views, fail to account for the nature and efficacy of icons in cyberspace. While these icons may be perceived to be emboldened from another dimension -- a spiritual one according to those who believe and practice iconography as handed down from the Byzantine era - Byzantine icons have found little place in the twenty-first 
century. According to Tomaselli and Scott, today's icon is most often expected to be "a celebrity or cult object" (2009, p. 17).

An icon today most readily identifiable as such may also be a block of pixels on a computer screen linking the user with an application or function as part of a set of often related iconological suppositions. Creation of these expressive elements is an easy process; they are also standard industry fare for the graphical user interface (GUI) driving computer applications, Web-based and cell phone technologies, and pretty much any interactive computing process that requires the user to click an object in order to gain access to what lies beneath its symbolic representation.

For Gombrich, iconology had been, "since the pioneer studies of Erwin Panofsky, the reconstruction of a programme rather than the identification of a particular text" $(1972$, p. 3). When defining iconology, Gombrich indicated the role and intention of the iconologist as being concerned with three areas of inquiry: meaning, significance, and implication. These relevant foundational considerations cross over to the study of iconics and iconicology since the 'programmed' phenomenon of the iconic in digital media is its perpetual re/construction.

Media iconics, along with their inherent dangers, are categorical evidence in Gombrich's build on premises put forth by E. D. Hirsch regarding classification of symbols into genres and categories. Gombrich notes the inherent dangers when "as in literature, an initial mistake in the category to which the work belongs, or worse still, ignorance of possible categories will lead the most ingenious interpreter astray" (p. 5). This pitfall awaits the interlocutor for media iconics, as they are subject to a similar process for misinterpretation.

With their semiological roots spread across the disciplines of rhetorics, semantics, and pragmatics, these new icon structural entities I refer to as media iconics, play a critical role in the identification and determination of motives and incentives across digital media channels as media profit ventures, terrorist wartime tools for their objectives, and as digital media artillery.

\subsubsection{Icon(ic)(R)Evolution}

Recognizing that "the meaning of terrorism" is "a communicative, rhetorical process" in the finale to his book, Communicating Terror: The Rhetorical Dimensions of Terrorism, may seem to be an odd starting point for an exegesis of mediated messaging as visual rhetoric evidenced through iconics; however, it truly is an appropriate starting point for Joseph Tuman (2003, p. 115). While most media iconics may be constituted by a sea of media content not considered terrorism or a threat to global peace objectives, current repetitive deployment of iconic images to an anxious and waiting global audience testifies to the veracity of Tuman's definition.

Difficulty defining linguistic terms in analysis of media images has always been a precarious acct. It is not possible today to talk of a 'war on terrorism' without realizing the implications that suggest. Rampton and Stauber claim that such talk is "doublespeak" that "often suggests a noble cause to justify the death and destruction" (2003, p. 118) and that "sometimes language is chosen for its ability to avoid the plain meaning of what its writers are talking about" (p. 120). These ambiguities are problematic enough across analog channels, and have held the world at bay in the past, yet their move into digitality adds that extra dimension of extrapolation along with other powerful, potentially visceral reactions that provide a new, digital rhetoric heretofore not experienced on the planet. And it is now everyday occurrence for everyone.

Since the meaning of a terrorist event is separate from the interpretation of a terrorist event, in part because the event itself is designed to be ambiguous, a large part of the terror is this actual ambiguity. This was most evident during the attack of September 11, 2001, when much of the world stood in shock and horror, mostly due to the repetitive, televised moment-by-moment account of the devastation and after effects. However, the same media that brought this horror to the rapt attention of the world, in at least one particularly iconic moment, at the same time broadcast the horror of the animated voices and faces of Palestinian women and children dancing jubilantly, as if drunken, in their streets. Still, this is atypical, as other Palestinians may be found in mourning following the September 11, 2001 attacks. 
The 9/11 attacks that brought the West and its supporters to a wake-up call meant something of high value to its revelers. U.S. political powers at the time made some rash judgments in an attempt to save face, salvage whatever could be, and blindly strike back. Still other antagonists took advantage of the milieu through deadly anthrax attacks. These attacks remain unresolved in their culpability, and in scope because of their contingency and impact on the global consciousness, they remain iconic with their stories and images archived in digitality. Images, even those digitized, that do not meet the criteria for iconicicity may be popular and even powerful, but they are not iconics.

Images and media contending for status as iconics express crucial, fundamental characteristics that are universally applicable for any individual media iconic. See Figure 2. Digital media icons consistently and emphatically exhibit intrinsic characteristics of iconic being:

- Ambiguity - Iconics are containers for multiple meanings in coded/cued semantics.

- Digitality - Iconics are instantly archivable and retrievable media of ones and zeros.

- Iconicity - Iconics are an overarching presence in the global consciousness.

- Profitability - Iconics are a functional commodity as newsworthy capital.

- Weaponry - Iconics are potential legitimized, repetitive ammunition and destroyers.

- Ubiquity - Iconics are accessible, promulgated, and powerful as universal entities.

The media iconic is repetitively ambiguous, and as such, harbors potential for attack on global consciousness. The iconic is capable of wielding terror at light speed across ubiquitous networks, also capable of providing profit for the merchants that sell its imagery and terror across media channels, capable of holding codes and cues for select audiences who perceive it differently -perhaps more reverently -- than other cultures and peoples. It is capable of endless digital reproduction, manipulation, archived database retrieval, and advanced psychosocial and political weaponry on its intended audiences.

Manuel Castells noted the root of this digital phenomenon in networked Internet access as it relates to culture. Castells claimed: "The emergence of a new electronic communication system characterized by its global reach, its integration of all communication media, and its potential interactivity is changing and will change forever our culture" (1996, p. 329). There are no naysayers today, just pundits and analyses of exactly how good or bad the effects of digital technologies are for culture. 


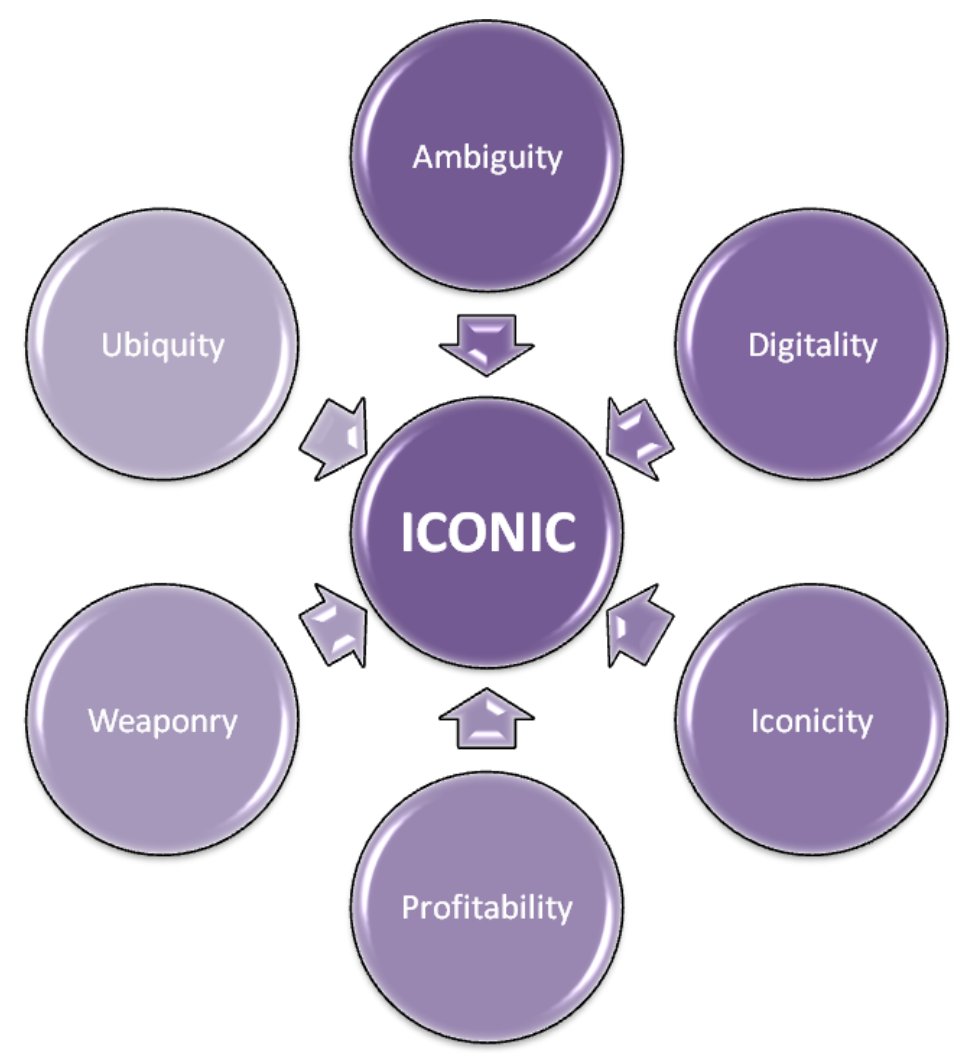

Figure 2: Model of an individual iconic as a construct of integrative media attributes

My word choice of ambiguity probably would be better as 'amultiguity;' but, apart from that being a mouthful, the dyadic contrast for working with these pages left me to settle for ambiguity as it has a limited scope much more manageable than multiplicity, which is exponential and unable to provide control necessary for this subject. Jacques Rancière noted this phenomenon of multiplicity with a limited perspective in The Future of the Image when he contended that the image becomes a 'hyper-resemblance:'

"In short, the image is not merely double, it is triple. The artistic image separates its operations from the technique that produces resemblances. But it does so in order to discover a different resemblance en route - a resemblance that defines the relation of a being to its provenance and destination, one that rejects the mirror in favour of the immediate relationship between progenitor and engendered: direct vision, glorious body of the community, or stamp of the thing itself. Let us call it hyper-resemblance. (2007, p. 8)

Unlike Rancière, however, I see iconics as exponential rather than triadic. Their intrinsic capacity for unlimited growth potential further complicates their presence. Furthermore, I do not see the image separating its function from the technique that replicates its mimesis; but rather, image as perpetual self-mimicry: irruptive pulsations on a permanently archived presence in digitality.

\subsubsection{The Transformative Icon}

An iconic as an instantiation rising above contingency becomes "glorified." It maintains this transfigured state as long as it is pullable or pushable -- in principle -- from or into the global consciousness, which means it exists as long as there is a cyberspace. Because of digital technologies and immediate archivability, the only way for an iconic today to lose potentiality in its transfigured state is for all members who participate in the global consciousness at any time in history to die off. 
Contingency to an iconic may allow its power or aura to seem to disappear -- perhaps when its myth is no longer valid, though digitality does not allow this to happen. Jean Baudrillard claimed that,

"What distinguishes the analogue image from the digital is that within it a form of disappearance is in play, a form of distance, of freezing of the world - that nothingness at the heart of the object which Warhol spoke of" takes place (2005, p. 97)

Furthermore, because of extant digital technologies and their immediate archivability, there is no way for an iconic to lose the potentiality of its transfigured state, since it exists as a dynamic irruption capable of technological resurrection upon summons.

My tentative conclusion is, despite any loss in original aura due to iconic contingency in the global consciousness, once an element of media crosses over to the iconic, its digital archivability, reproducibility, and inherent reincarnation and virality as an iconic keep it alive and kicking. It is always available for registry from the global consciousness to individual or group consciousness or vice-versa.

Additional criteria that validate an iconic are newly available characteristics that relegate to an icon once it enters digitality, especially related to terrorism and media. Still, what would be helpful today would be recognition of a common signature among terrorists - but not common to others identifiable in their use of media; what digitality of media iconics allows us to recognize as critical to the iconic creation process. Because of digitality, the myth of an icon does not diminish; however, it subscripts a media iconic.

In order to describe and analyze how iconics convey meaning visually, i.e., provide an iconology, or iconicology, it helps to begin to draw upon traditional theories of Erwin Panofsky. Charles Peirce, and Roland Barthes, among others, for the contingent evolutionary tract of the icon over the past century, since iconics as visual imagery or rhetoric construct systematically within an iconographical process of categorization.

Television and the Internet have provided a far different venue for iconicological analysis than Panofsky put forth in the mid-50s. Yet it was McLuhan in "War of the Icons" from Understanding Media: The Extensions of Man -- published nearly a decade later than Meaning in the Visual Arts -who was first to analyze television iconography as weaponry, or at least to express that sentiment emphatically for a global village audience.

Despite his critics, McLuhan's collection of essays designates as prophetic, and he hails as a mystic. Perhaps there is no better indication of the brilliance, intuition, and relevance inherent in McLuhan's varied writings than adaption of their value to this present age in considering symbiotic roles of the media, iconics, and terrorism.

While there are many ways today to approach a systematic semiological determination for an iconic that exhibits characteristics evident in semiotics, I address some of those determinants and processes in other related publications on iconics. My proposal here has been to introduce iconics as a digital gestalt phenomenon resulting from collusion between terrorism and the media.

On a final note here I just want to say that, symbolism for iconics related to terrorism is in a sense a 'reverse-symbolism' because a primary goal of the religious extremist considered rogue terrorist is an iconoclastic strike at the symbolic power structure. That the Twin Towers fell with such finality was a huge iconoclastic victory against the West's most prolific structural symbolism for the power of capitalism: the corporation and globalism; or, more precisely, globalization.

\section{References}

Baudrillard, J. (2005). The intelligence of evil or the lucidity pact. Oxford, UK; New York, NY: Berg.

Benjamin, W. (1969). The Work of Art in the Age of Mechanical Reproduction. In Illuminations: Essays and reflections. New York, NY: Schocken.

Castells, M. (1996). The rise of the network society. Cambridge, MA: Blackwell Publishers. 
Davies, D., Bathurst, D., \& Bathurst, R. (1990). The telling image: The changing balance between pictures and words in a technological age. Oxford, UK: Clarendon.

Eco, U. (1984). Semiotics and the philosophy of language. Bloomington: Indiana University Press.

Gombrich, E. H. (1972). Symbolic images. London: Phaidon.

Habermas, J., Derrida, J., \& Borradori, G. (2003). Philosophy in a time of terror: Dialogues with Jürgen Habermas and Jacques Derrida. Chicago, IL; London, UK: University of Chicago Press.

Lasswell, H. D. (1938). Propaganda technique in the world war. New York, NY: P. Smith.

van Leeuwen, T. (2006). War rhetoric. In K. Brown (Ed.), The encyclopedia of language \& linguistics. (Vol. 13, pp. 516-520). Amsterdam, NL; Boston, MA: Elsevier.

McLuhan, M. (2001). Understanding media: The extensions of man. London, UK: Routledge.

Nichols, B. (1988). The Work of Culture in the Age of Cybernetic Systems. Screen, 29(1), 22-46.

Panofsky, E. (1955). Meaning in the visual arts: Papers in and on art history. Garden City, NY: Doubleday.

Rampton, S., \& Stauber, J. C. (2003). Weapons of mass deception: The uses of propaganda in Bush's war on Iraq. New York, NY: Jeremy P. Tarcher, Penguin.

Rancière, J. (2007). The future of the image. London, UK; New York, NY: Verso.

Tomaselli, K.G. \& Scott, D. (Eds.) (2009). Cultural icons. Walnut Creek, CA: Left Coast Press.

Tuman, J. S. (2003). Communicating terror: The rhetorical dimensions of terrorism. Thousand Oaks, CA: Sage.

Virilio, P. (1991). The lost dimension. New York, NY: Semiotext(e).

Weitzmann, K. (1978). The icon: Holy images - sixth to fourteenth century. New York, NY: G. Braziller.

\section{About the Author}

Steven John Thompson

Steve is currently a Visiting Assistant Professor in English at Towson University. A former journalist, he has been an iconicologist engaged in the academic research of media iconics since 2006. For further information, visit http://iconics.ws. 